\title{
ARTIGOS \\ Interoperabilidade e Violência Institucional no Sistema Prisional
}

\author{
Por Andremara dos Santos, Juíza Auxiliar da Presidência do Conselho Nacional de Justiça (CNJ)
}

\begin{abstract}
Resumo: Este artigo analisa a relação entre a interoperabilidade de sistemas tecnológicos e a violência institucional no sistema prisional como um todo. É fruto da dissertação apresentada no Mestrado Interinstitucional em Segurança Pública, Justiça e Cidadania, realizado em parceria com a Universidade Federal da Bahia, o Tribunal de Justiça da Bahia, e a Secretaria de Segurança Pública do Estado da Bahia. Optou-se pela realização de estudo de natureza qualitativa, por meio dos procedimentos de revisão de literatura científica e revisão jurisprudencial e legislativa nas áreas penal, processual penal e de direitos humanos. Os resultados da pesquisa evidenciaram que a ausência de sistemas tecnológicos dotados de interoperabilidade nos órgãos do sistema de justiça criminal impede a gestão eficiente do sistema prisional e favorece a violação dos direitos humanos e fundamentais das pessoas em situação de prisão, ao dificultar ou inviabilizar o exercício dos seus direitos e tornar invisível a violência imposta.
\end{abstract}

PALAVRAS-CHAVE: Interoperabilidade. Sistema de justiça criminal. Sistema prisional. Violência institucional. Direitos humanos.

Abstract: This article examines the relationship between interoperability of technological systems and institutional violence in the prison system as a whole. It is the result of the dissertation presented in the Interinstitutional Masters in Public Safety, Justice and Citizenship held in partnership by the Federal University of Baha, the Court of Justice of Bahia and Secretary of Public Security of the State of Bahia. A qualitative approach was chosen, carried out through scientific literature review procedures, judicial and legislative review in criminal law area, criminal procedure and human rights. The survey results showed that the lack of use of interoperable technological systems by criminal justice system agencies prevents the efficient management of the prison system and promotes the violation of human and fundamental rights of those people in prison situation, by hindering or making impracticable the exercise of their rights and makes invisible the violence imposed.

KEYWORDS: Interoperability. Criminal justice system. Prison system. Institutional violence. Human rights.

\section{Introdução}

Este artigo é originário da dissertação apresentada no Mestrado Interinstitucional em Segurança Pública, Justiça e Cidadania realizado pela Universidade Federal da Bahia em parceria com o Tribunal de Justiça e a Secretaria de Segurança Pública daquele estado. Tem por objeto a análise da relação existente entre a interoperabilidade de sistemas tecnológicos e a violência institucional decorrente da não observância das normas de proteção aos direitos humanos no sistema prisional da comarca de Salvador.

O estudo foi realizado na linha de pesquisa "criminalidade e vitimização", a partir da situação identificada na comarca de Salvador, onde foi constatado que os sistemas tecnológicos de que se valiam os órgãos do sistema de justiça criminal (as polícias, o ministério público, o judiciário, e o sistema prisional) não eram dotados de interoperabilidade, gerando como consequência a violação à Constituição Federal (CF), aos tratados internacionais e à legislação de proteção dos direitos humanos vigentes no ordenamento jurídico brasileiro (BRASIL, 1988; OEA, 1969, ONU, 1977 e 1985).

\section{Interoperabilidade e sistema prisional}

\subsection{0 conceito interoperabilidade}

O termo interoperabilidade é oriundo do campo da ciência da computação, mas em uma relação de permuta linguística foi se especificando gradualmente como um capital comum a vários grupos, tanto na área privada como na pública, servindo, inclusive, como ferramenta do campo de poder (BOURDIEU, 2007) do tecnocolonialismo decorrente da revolução tecnocientífica (BATISTA, 2007) e ferramenta, por excelência, de eficiência na gestão pública e privada.

Embora as produções científicas contemporâneas discutam o tema da interoperabilidade, se concentram na aplicação deste conceito nas áreas das ciências de tecnologia e processamento de dados, negócios, informações e, em matéria de governança eletrônica (e-Government), nas áreas de telecomunicações, transportes, biblioteconomia e saúde, não tendo privilegiado o enfrentamento da questão no contexto do sistema de justiça criminal.

A interoperabilidade é um instrumento tecnológico de governança e de gestão recomendado pela ONU como ferramenta de desenvolvimento sustentável (ONU, 1975) e adotado pelo Brasil como política pública da administração federal desde 2003 (BRETAS et al, 2010). 
Como tal, pode garantir maior efetividade às ações da administração pública, possibilitando, conforme Santos (2010):

a) a interconexão em substituição a soluções isoladas;

b) maior eficiência, por meio da redução dos custos de transação e de tempo, além do aumento da participação dos agentes envolvidos; e,

c) efetiva responsividade, mediante a resolução mais rápida dos problemas, como consequência do melhor acesso às informações.

No Brasil, a versão 2014 do documento que serve de referência para a arquitetura básica da estratégia de governança eletrônica do governo federal (arquitetura e-PING - Padrões de Interoperabilidade de Governo Eletrônico), relaciona os conceitos e noções operativas de interoperabilidade que fundamentaram o entendimento do governo brasileiro sobre a matéria, dos quais destacam-se os seguintes:

Intercâmbio coerente de informações e serviço entre sistemas. [...] . (Governo do Reino Unido);

Habilidade de transferir e utilizar informações de maneira uniforme e eficiente entre várias organizações e sistemas de informação. (Governo da Austrália);

Habilidade de dois ou mais sistemas (computadores, meios de comunicação, redes, software e outros componentes de tecnologia da informação) de interagir e de intercambiar dados de acordo com um método definido, de forma a obter os resultados esperados. (ISO). (BRASIL, 2013, p. 6)

A interoperabilidade, portanto, configura-se como a soma de todos os elementos que integram esses conceitos e noções, tendo por meta a viabilização da atuação dos sistemas de forma cooperativa. Não se trata apenas da integração de sistemas e de redes, da troca de dados entre sistemas ou definição de tecnologia compatível, mas de um conceito que pressupõe o engajamento das pessoas num "esforço contínuo para assegurar que sistemas, processos e culturas de uma organização sejam gerenciados e direcionados para maximizar oportunidades de troca e reuso de informações" (BRASIL, 2013, p. 6.).

Como explicitado na versão 2015 do Documento de Referência e-PING, pode-se entender a interoperabilidade como a "capacidade de diversos sistemas e organizações trabalharem em conjunto (interoperarem) de modo a garantir que pessoas, organizações e sistemas computacionais interajam para trocar informações de maneira eficaz e eficiente" (BRASIL, 2014, p. 3), evitando retrabalho e agilizando a resposta adequada a cada demanda.

Entretanto, a interoperabilidade não se restringe apenas a uma capacidade técnico-operativa. É uma categoria de caráter relacional cuja amplitude da sua aplicabilidade, dependerá do nível de atuação demandada.

Neste sentido, Gradmann (2008) afirma que a interoperabilidade pode ser considerada em diferentes níveis de abstração e que as distinções a serem feitas na sua aplicação atravessam várias dimensões que, em uma escala, vão de uma perspectiva muito concreta para uma muito abstrata, assim ilustrada:

Figura 1: Dimensões da interoperabilidade.

\section{INTEROPERABILIDADE NO PLANO ABSTRATO -} ORGANIZACIONAL OU POLÍTICO

Interoperabilidade semântica - o nível mais elevado, permite acessar classes similares de objetos e serviços através de múltiplos sites, com multilinguagem e capacidade de interpretação dos dados recebidos.

Interoperabilidade funcional ou pragmática - baseia-se em um conjunto comum de funcionalidades primitivas ou em um conjunto comum de definições de serviços.

Interoperabilidade sintática - permite a troca de metadados e elementos de protocolos.

Interoperabilidade técnica - atua no nível de ferramentas comuns, interfaces e infraestrutura, facilitando o acesso e a uniformização de procedimentos.

INTEROPERABILIDADE NO PLANO CONCRETO - DO FUNCIONAMENTO E POSSIBILIDADE DE CONEXÃO DOS SISTEMAS TECNOLÓGICOS DE INFORMAÇÃO

Fonte: Adaptado pela autora a partir de Gradman,2008.

A interoperabilidade, na verdade, é uma categoria do campo da tecnologia da informação e expressa a capacidade de sistemas de informação heterogêneos interagirem (interoperarem) a partir de uma base comum que lhes permita trabalhar em conjunto, compartilhando e resolvendo as diferenças existentes de modo cooperativo, mediante a interpretação e compreensão do significado técnico, sintático, pragmático e semântico de dados de diferentes modelos e estruturas. Constitui-se, na verdade, em fator necessário para o desenvolvimento econômico e social, além de elemento essencial para a eficiência da governança na área pública e privada.

\subsection{Sistema prisional}

O sistema prisional constitui-se em um subsistema integrante do sistema penitenciário do Estado, que inclui também os subsistemas das penas restritivas de direito e das medidas de segurança.

Em sua inteireza, o sistema penitenciário abrange o sistema das medidas e penas diversas da prisão ou alternativas a esta para além do sistema prisional, que é o encarregado da gestão e execução da pena de prisão, aplicada em caráter definitivo ou cautelarmente, por antecipação.

Por sua vez, o sistema penitenciário integra, como um subsistema, o sistema de justiça criminal, aqui compreendido como o conjunto de órgãos do Estado responsáveis pelo controle penal formal,.

Conquanto existam divergências quanto à qualificação e quantidade dos órgãos integrantes do sistema de justiça criminal, entende-se aqui o sistema de justiça criminal como sendo o sistema dinâmico de funções constituídas pelo direito penal responsável pela aplicação das normas 
relativas ao processo penal, isto é, o conjunto de órgãos constituídos pelas agências policiais, pelo ministério público, pelo judiciário e pelo sistema penitenciário, que atua desde a investigação criminal até a execução da pena ou da medida de segurança, passando pelo julgamento criminal propriamente dito (BARATTA, 2002, p.161).

Este critério específico para definição do sistema criminal foi adotado, pelo fato de o artigo ter como foco a atuação das instâncias formais constituídas pelo Estado e a totalidade do sistema de aplicação da justiça penal, na perspectiva do que nos fala Dias (2010, p. 30), ao afirmar que estes órgãos controlam o inteiro "processo de produção" da delinquência, excetuada a fase da elaboração legislativa.

O sistema prisional, com os seus órgãos, agentes e as diversas espécies de estabelecimentos destinados ao encarceramento de pessoas, constitui-se no setor do poder executivo incumbido da gestão do cumprimento da pena de prisão. Atua, portanto, segundo a legislação brasileira de referência - a Constituição Federal, o Código Penal (Decreto-Lei 2.848, de 7 de dezembro de 1940), o Código de Processo Penal (Decreto-Lei 3.689, de outubro de 1941) e a Lei de Execução Penal (Lei 7.210, de 11 de julho de 1984) na execução das decisões criminais que impõem a pena de prisão de forma definitiva ou, cautelar e antecipadamente, antes do julgamento ou do trânsito em julgado da sentença condenatória.

Assim sendo, a gestão do sistema prisional pelo Estado, como consequência do monopólio da aplicação da lei penal, o torna responsável direto pela garantia dos direitos de que são titulares as pessoas encarceradas, direitos estes cuja observância passa, também, mas não só, pela existência de sistemas tecnológicos interoperáveis, dotados de capacidade para a realização do armazenamento, de conectividade e da possibilidade de compartilhamento dinâmico de informações, de modo a assegurar o respeito e o cumprimento correto das decisões criminais com respeito às datas de vencimento das penas e dos benefícios previstos na legislação, com observância da efetiva individualização da pena (mesmo daquela aplicada por antecipação).

A ausência de eficiência do Estado nesse encargo gera um tipo de violência qualificada por Baratta (1990) como institucional.

\subsection{Sistema prisional e violência institucional}

Abbagnano (1998, p. 1002) conceitua violência como a ação contrária à ordem moral, jurídica ou política, sintetizando a força de algumas das variações que o termo pode assumir.. Para Baratta (1990) violência é toda repressão de necessidades reais, tornando-se institucional quando o agente que a produz é um órgão do Estado.

No sistema prisional, a violência se dá por diversas vias. Este sistema, autorizado legalmente à coarctação da liberdade daqueles que custodia (coação legal, portanto), é obrigado a gerir adequadamente o cumprimento da pena, assegurando ao preso todas as assistências legalmente previstas, consistentes na prestação de atendimento jurídico, sanitário, social, religioso, laboral e educacional, em um complexo de ações interdisciplinares, voltadas à viabilização da participação construtiva das pessoas apenadas ou submetidas às medidas de segurança, por ocasião do seu retorno à comunhão social (BRASIL, 1984), vedada que é pelo art. $5^{\circ} \mathrm{XLVII}, b$, da Constituição Federal a existência de pena de caráter perpétuo (Brasil, 1988)).

Portanto, a correta atuação do sistema prisional pressupõe a gestão eficiente de todas as informações necessárias à classificação e realização do atendimento e tratamento penitenciário das pessoas custodiadas ou internadas. Tudo de acordo com as necessidades reveladas pela anamnese biopsicossocial a que deve ser submetida toda pessoa presa, especialmente se condenada no regime fechado, quando obrigatoriamente deverá ser submetida ao exame criminológico, previsto no art. $8^{\circ}$ da Lei 7.210/84 (BRASIL, 1984)

Neste contexto, a ausência de informações e a má qualidade ou inexistência de comunicação e compartilhamento das informações sobre a pessoa presa, consubstancia uma espécie de violência institucional por omissão ou ineficiência do Estado na gestão da pena de prisão de acordo com a lei, por fazer com que a pena imposta implique em uma retribuição mais aflitiva no campo pessoal e jurídico, do que o legalmente permitido.

Esta violência institucional, que se materializa por meio da falta de eficiência na gestão da pena de prisão, contraria as garantias e direitos previstos no sistema legal, supralegal e constitucional, e é praticada ou reproduzida pelo próprio sistema punitivo (CARVALHO, 2013). Assim, a população carcerária é vitimizada ao ter acentuada ou prolongada a exposição da pessoa presa ao sofrimento físico, material e psicológico descritos por Almeida e Paes-Machado (2013), em estudo sobre os processos sociorganizacionais de vitimização de internos da maior dentre as unidades prisionais da Bahia, a Penitenciária Lemos Brito (PLB).

Esse tipo de violência acentua a vulnerabilidade das pessoas em situação de prisão, atingindo direitos fundamentais não restringidos ou não restringíveis pela decisão judicial autorizadora do encarceramento, como a supressão do direito à liberdade de locomoção por tempo superior ao legalmente previsto ou determinado, a violação do direito à incolumidade física e do direito à não submissão a penas cruéis ou degradantes.

No primeiro caso, a violência institucional decorre do aumento da duração da custódia provisória ou definitiva, por exemplo, em razão da ausência de informações relativas à vigência de mandado de prisão, à homonímia e à localização física do réu, ou, ainda, em virtude da demora na obtenção destes e de outros dados por meio de correspondência escrita em meio físico ou eletrônico, não automatizado ou interoperável.

Já na segunda e terceira situações, a violência é decorrente da ausência ou do tratamento inadequado das informações necessárias à produção de resultados e decisões (concretos, quantitativos e qualitativos) sobre as pessoas submetidas à prisão. Gera a possibilidade de ocultação da omissão do Estado em gerir adequadamente o sistema prisional em conformidade com as convenções internacionais, tornando inexigíveis medidas como a separação das pessoas presas de acordo com o seu perfil, a observância do espaço legal mínimo necessário à preservação e ao respeito da sua integridade física e moral e, também, do prazo para deferimento dos seus direitos. 


\section{Responsabilidade institucional do estado democrático de direito em relação ao sistema prisional}

Resultado da evolução dos processos organizatórios do poder político, o Estado Democrático de Direito, como instituído na Constituição de 1988, reúne em torno da organização jurídico-política denominada Estado (CANOTILHO, 1999), dois qualificativos que nem sempre andaram juntos, mas que, nos tempos atuais, estão necessariamente imbricados: direito e democracia.

O Estado de Direito, considerado isoladamente, remete ao valor da eliminação da arbitrariedade no relacionamento do Estado com os cidadãos, em uma inversão da relação entre poder e direito, que Zagrebelsky (2009, p. 21) resume na máxima no más rex facit legem, sino lex facit regem, para acentuar a limitação do poder do governante pelas leis e a liberdade dos cidadãos pela vinculação da Administração Pública à lei, enquanto norma geral e abstrata.

Traçado o percurso histórico do que denominou de ideia de um Estado domesticado pelo direito no Ocidente, Canotilho (1999) demonstrou ser o Estado de Direito um paradigma jurídico-político da cultura ocidental e do Estado liberal do Ocidente, arquitetonicamente forjado com base no consenso sobre princípios e valores que formam a juridicidade estatal.

Esta juridicidade estatal teria os seguintes fundamentos:

Governo de leis (e não de homens) gerais e racionais, organização do poder segundo o princípio da divisão de poderes, primado do legislador, garantia de tribunais independentes, reconhecimento de direitos, liberdades e garantias, pluralismo político, funcionamento do sistema organizatório estadual subordinado aos princípios da responsabilidade e do controlo, exercício do poder estadual através de instrumentos jurídicos constitucionalmente determinados (CANOTILHO, 1999, p. 7.).

Ele demonstrou também a sobreposição das influências de múltiplas nações na construção do paradigma, revelando que a expressão Estado de Direito, conquanto oriunda do Rechtsstaat alemão, compila em seu conteúdo os valores e ideais do rule of law dos ingleses, do Estado de legalidade dos franceses e do Estado constitucional dos americanos.

Canotilho afirmou os diversos planos de materialização do Estado de Direito e destacou como de sua essência as seguintes dimensões:

1) 0 império do direito, com a conformação dos esquemas de organização do poder, do Estado, dos governantes e das autoridades aos ditames do direito e ao exercício dos poderes públicos por meio de instrumentos jurídicos institucionalizados por uma ordem jurídica fundada em princípios jurídicos indisponíveis que lhe dão validade e legitimidade.

2) Um Estado de direitos fundamentais pessoais, políticos e sociais, reconhecidos e consagrados como tal pela Constituição, com a possibilidade de serem exigidos, obrigando o próprio legislador a respeitá-los e a observar o seu núcleo essencial, sob pena de nulidade das próprias leis.

3) Observância do princípio da justa medida, ou princípio da proibição do excesso, como regra de razoabilidade, de proporcionalidade e de necessidade, na atuação de todos os poderes do Estado.

4) Garantia do princípio da legalidade da administração.

5) Responsabilidade do Estado por seus atos, porque, no Estado de Direito supera-se a fórmula absolutista da irresponsabilidade e da infalibilidade dos governantes, para afirmar-se que o Estado deve responder civilmente pelos danos incidentes na esfera jurídica dos particulares, independentemente de a atuação ser legítima ou lícita.

6) Garantia da via judiciária, mediante o acesso livre ao direito e aos tribunais, com a garantia de um juiz legal, independente e imparcial.

7) Segurança e confiança, traduzidas na fiabilidade, na clareza, na racionalidade e na transparência da atuação dos poderes públicos.

O constitucionalista português, Canotilho (1999), ao lembrar os exemplos negativos do nazismo, do fascismo, do Estado Novo português e do Estado falangista espanhol, afirmou a inexistência de antinomia entre Estado de Direito e democracia, declarando que "o Estado de direito ou é Estado democrático e social ou será um Estado de legalidade reduzido a um esqueleto constituído por princípios e regras formais", sem a legitimação democrática conferida pelo Estado constitucional assentado no poder constituinte do povo.

[...] o Estado de Direito transporta princípios e valores materiais razoáveis para uma ordem humana de justiça e paz. São eles: a liberdade do indivíduo, a segurança individual e colectiva, a responsabilidade e responsabilização dos titulares do poder, a igualdade de todos os cidadãos e a proibição de discriminação de indivíduos e grupos. Para tornar efectivos estes princípios e estes valores o Estado de direito carece de instituições, de procedimentos de acção e de formas de revelação dos poderes e competências que permitam falar de um poder democrático, de uma soberania popular, de uma representação política, de uma separação de poderes, de fins e tarefas do Estado (CANOTILHO, 1999, p.7).

\subsection{Direitos humanos, direitos fundamentais, sistema prisional e interoperabilidade. Quid juris?}

De acordo com Habermas (2003, p. 153), no "Estado de direito [...] o "poder das leis" exige que a formação democrática da vontade não se coloque contra os direitos humanos positivados na forma de direitos fundamentais". Vale dizer, os direitos humanos são o limite da autonomia da vontade privada e da pública.

Para Müller (2007, p.164), inclusive, os direitos humanos constituem-se na base de um direito fundamental de última geração, que é o direito fundamental à democracia fundamentado nos direitos humanos.

Ainda segundo o autor da teoria estruturante do direito, na vertente da integralidade e da interdependência dos 
direitos humanos, como um todo,

[...]os direitos humanos nacionais e transnacionais oferecem uma base jurídica de resistência contra todas as formas de agressão e opressão política e militar, assim como contra a injustiça econômica e social que é considerada consequência da atual forma de globalização (MÜLLER, 2007, p.166).

O problema da efetivação dos direitos humanos, como alertou Lolita Aniyar de Castro (2005, p. 5), é que existe uma estreita relação entre conhecimento, controle, leis e poder. Por esta razão, conclui que as leis e as declarações sobre direitos humanos, somente em algumas ocasiões e a longo prazo, mostram alguma eficiência indenizatória ou punitiva frente a genocídios. Por outro lado, são investidos muitos recursos e tecnologias para o controle do terrorismo, porque, segundo a autora, os autores deste tipo de ação pertencem a estratos nacionais ou religiosos que não estão no poder: "Los controles se activan, como se sabe, cuando los poderosos de antes "pierden la guerra" (CASTRO, 2005, p. 5).

Declarando a incompatibilidade dos direitos humanos com sistemas políticos não democráticos, Müller (2007, p. 167) afirma, ainda, que "não pode ser empiricamente contestado que regimes autoritários e ditatoriais oprimem regulamente os direitos humanos".

Sendo assim, é responsabilidade institucional do Estado brasileiro, por constituir-se em um Estado democrático de direito que tem como um de seus fundamentos a dignidade da pessoa humana, velar, assegurar e garantir os direitos humanos positivados na Constituição Federal (BRASIL, 1988) e na legislação infraconstitucional, assim como nos tratados e convenções de que é parte, assegurando que às pessoas privadas de liberdade não seja dispensado tratamento desumano ou degradante, que torne cruel a pena privativa de liberdade legalmente prevista e imposta.

\subsection{A discussão da matéria na Corte Europeia de Direitos Humanos e no Supremo Tribunal Federal}

\subsection{A sentença do caso Torreggiani}

Exemplo de responsabilização jurídica do Estado por violação de direitos no sistema prisional, a sentença da Corte Europeia de Direitos Humanos que julgou o caso Torreggiani e Altri vs Italia (FRANÇA, 2013) reconheceu aos interessados o direito à indenização por danos sofridos por submissão a tratamento desumano e degradante nas prisões em que estiveram recolhidos na Itália, em decorrência da superlotação e das péssimas condições carcerárias que contrariam o disposto no art. $3^{\circ}$ da Convenção Europeia dos Direitos Humanos (CONSELHO DA EUROPA, 1950).

$\mathrm{Na}$ sentença proferida em procedimento piloto que reuniu sete queixas que tramitavam contra o Estado italiano no período de 06/08/2009 a 01/07/2010, ajuizadas por FermoMino Torreggiani, Bazoumana Bamba, Raoul Riccardo Biondi, Afrim Sela, Tarcisio Ghisoni, Mohamed El Haili e Radouane Hajjoubi (FRANÇA, 2013), o Tribunal Europeu de Direitos Humanos reconheceu a violação alegada e determinou que a Itália, no prazo de um ano, adotasse medidas idôneas a oferecer um melhoramento adequado e suficiente para eliminar a superlotação carcerária, em conformidade com os princípios da referida convenção e jurisprudência daquela corte.

Além disto, suspendeu, pelo prazo de um ano da data em que a referida sentença tornou-se definitiva, todos os procedimentos que tivessem por objeto único a superlotação carcerária e, por fim, reconheceu o dano e determinou o pagamento das indenizações que fixou, de acordo com o pedido e o caso de cada um dos recorrentes, no patamar entre $10.600,00$ a $23.500,00$ euros (FRANÇA, 2013).

\subsection{0 voto vista proferido no Recurso Extraordinário n. $\mathbf{5 8 0 . 2 5 2}$}

No Brasil, o Recurso Extraordinário n. 580.252, do Mato Grosso do Sul, também teve por objeto pedido de indenização formulado pela Defensoria Pública do Mato Grosso do Sul em favor de Anderson Nunes da Silva enquanto perdurassem o tratamento degradante e a superlotação a que estava submetido na prisão em que se encontrava, em contrariedade ao art. $5^{\circ}$, incisos III, X e XLIX, e $37, \S 6^{\circ}$, da Constituição Federal brasileira (BRASIL, 1988), que materializa o art. $5 .^{\circ}$ da Convenção Americana sobre Direitos Humanos (OEA, 1969).

A Defensoria Pública requereu a condenação do Estado ao pagamento de um salário mínimo mensal ao recorrente, enquanto perdurasse a situação retratada e impetrou recurso extraordinário da decisão que, em sede de embargos infringentes, reformou o acórdão da apelação que condenara o Estado a pagar a quantia de R\$ 2.000, a título de danos morais, julgando improcedente o pedido mediante a aplicação da teoria da "reserva do possível", sob os argumentos da cessação do dano causado e de que a sua reparação impunha a necessidade da realização da implementação de políticas públicas que exigiriam a "disposição de verba orçamentária" (BRASIL, 2015a).

0 recurso extraordinário foi protocolado em 5 de março de 2008, e em 18 de fevereiro de 2011 o Supremo Tribunal Federal reconheceu a existência de repercussão geral da questão constitucional suscitada. Na sessão de julgamento realizada em 18 de dezembro de 2014, depois do voto do Relator, o Ministro Teori Zavascki deu provimento ao recurso para restabelecer o juízo condenatório nos termos e nos limites do acórdão que julgou a apelação. 0 Ministro Roberto Barroso pediu vista dos autos e proferiu voto vista que traduz materialmente o alcance do tema da interoperabilidade tecnológica e operacional na gestão do sistema prisional.

Este voto fez a interlocução entre a situação carcerária da Itália e do Brasil e dialoga com a solução jurisprudencial da Corte Europeia de Direitos Humanos e com a solução legislativa adotada pela Itália para dar cumprimento à Sentença Torreggiani, como ficou conhecido aquele provimento.

O Ministro Roberto Barroso, depois de avaliar o impacto e o desdobramento da decisão da Corte Europeia de Direitos Humanos para a Itália, acompanhou a essência do voto do Relator, dele divergindo, contudo, na forma de reparação do dano, por entender que "a entrega de uma indenização pecuniária confere uma resposta pouco 
efetiva aos danos morais suportados pelos presos" (Item 15), podendo acarretar a multiplicação de demandas idênticas, com tendência ao agravamento das violações à dignidade humana dos encarcerados pela utilização dos recursos escassos do Estado para a reparação monetária demandada, inclusive porque inexiste um critério para valoração deste dano e é vultoso o número de pessoas recolhidas nas prisões.

Nesta linha de raciocínio, o Ministro reconheceu como incontroversa tanto a efetiva violação à dignidade da pessoa humana, quanto os danos morais suportados pelo recorrente, assim como a existência da responsabilidade civil do Estado pelas condições desumanas de encarceramento comprovadas nos autos por relatório da Vigilância Sanitária do Município, por documento do Departamento Penitenciário Nacional e por Decreto editado pelo Governador do Estado recorrido.

Declarou, ainda, que o dever de indenizar os danos causados decorre de norma constitucional aplicável direta e imediatamente, independentemente da execução de políticas públicas ou de qualquer outra providencia estatal para sua efetivação.

Afirmou, também, não ser aplicável a teoria da reserva do possível a esse dever, inclusive porque, não poderia ela ser empregada para anular direitos fundamentais conferidos pela Constituição, como é o caso do direito de toda pessoa presa à integridade física, ao direito de não ser submetido a tratamento desumano ou degradante, e de ter assegurado o direito a indenização pelo dano material ou moral decorrente da violação a direito fundamental não afetado pela sentença penal condenatória.

Ato contínuo, o Ministro Roberto Barroso apresentou solução inspirada pelo Decreto-Lei 92, de 26 de junho de 2014, convertido na Lei 117, de 11 de agosto de 2014, da República Italiana, editados como providência concreta face às determinações constantes da Sentença Torreggiani, que instituiu a remição da pena como uma das formas de reparação do dano decorrente do descumprimento do art. $3^{\circ}$ da Convenção Europeia dos Direitos do Homem, à razão da redução de 1 dia de pena, por cada 10 dias sob detenção em condições desumanas ou degradantes, decorrentes da superlotação.

Em seu voto, o Ministro Barroso defendeu a reparação do dano moral verificado naquele caso em concreto mediante prestação in natura consistente na remição de 1 dia da pena por cada 3 a 7 dias de cumprimento de pena em condições degradantes, a serem fixados pelo Juízo da Execução, proporcionalmente aos danos suportados pelo preso, variando a escala de acordo com o nível de violação. Isto porque, afirmou o Ministro, o quociente a estabelecer a quantidade de dias remidos não pode ser inferior ao utilizado para a remição de pena pela leitura, "sob pena de barateamento da dignidade do preso", pois, "não se pode admitir que a compensação a que o preso faz jus pela submissão a condições desumanas de detenção seja menor do que a que ele obteria pela leitura de um livro", de acordo com a Portaria Conjunta DEPEN/CJF 276/2012 (BRASIL, 2015a).

A reparação do dano mediante pecúnia somente ocorreria, se vencedora a tese do voto vista, nos casos em que a pessoa requerente já houvesse cumprido integralmente a pena e não the fosse mais aplicável a remição, devendo, nesta hipótese, a questão ser decidida pelo juízo cível competente.

Porém, além de propor esta tese, com os efeitos inerentes ao instituto da repercussão geral, o voto-vista, destacou o "caráter estrutural e sistêmico das graves disfunções do sistema prisional brasileiro" que analisou detalhadamente, afirmou que a superação da violência institucional consistente neste "verdadeiro estado de coisas inconstitucional, exige a articulação de todas as esferas de poder (Item 140)", e elencou diversas medidas para redução da superlotação (Item 62), para o rompimento da lógica do encarceramento (Item 65) e para o suprimento das graves "deficiências na estruturação e funcionamento dos presídios" (Item 66).

Neste último item, declarou que, além da melhoria da estrutura física, é necessário o aperfeiçoamento do funcionamento dos estabelecimentos penais, das assistências prestadas de acordo com as exigências da Lei de Execução Penal e do monitoramento e gestão dos presídios, por meio, dentre outras medidas, "da implantação de um sistema informatizado unificado, que permita o registro, o acompanhamento e o controle da execução penal dos detentos de todo o país" (grifo nosso).

É neste ponto que este voto se afina com o objeto deste artigo e the confere estrutura dialógica para responder à pergunta que the serve de fundo, que é a de saber como a interoperabilidade dos sistemas tecnológicos utilizados pelas agências do sistema de justiça criminal se relaciona com a violência institucional perpetrada no sistema prisional.

Isto porque, além de ser exemplo do diálogo entre as fontes constitucionais e legislativas de Estados diversos, o referido voto, embora vencido, relacionou a utilização de um sistema tecnológico "unificado" como recurso necessário para o monitoramento das situações individualizadas de cada pessoa presa e gestão do sistema carcerário como um todo e para a garantia do respeito a direitos fundamentais como a integridade física e moral da pessoas em situação de prisão, tal como reconhecido nas convenções regionais sobre direitos humanos, ali analisadas.

Em outras palavras, serve para demonstrar a necessidade do uso da interoperabilidade como recurso para garantia da integração, coordenação, compartilhamento de dados, conectividade e sincronicidade das ações dos órgãos do sistema de justiça criminal e como meio de melhorar e viabilizar a governança do sistema prisional, de acordo com os ditames da Convenção Americana sobre Direitos Humanos e das Regras Mínimas para Tratamento de prisioneiros (OEA, 1969; ONU, 1977).

Em suma, o voto vista do Ministro Barroso no RE 580.252, comprovou a necessidade da utilização de recurso tecnológico interoperável para o "registro, - acompanhamento e o controle da execução penal dos detentos de todo o país", permitindo chegar-se à conclusão de que a interoperabilidade lógica, tecnológica e operacional dos subsistemas, processos e culturas que integram o sistema prisional pode ser um fator essencial à prevenção e controle positivo da violência institucional 
neste ambiente, tendo em vista que o controle legítimo da violência, de qualquer espécie, "é um dos grandes marcos de um governo democrático" (PINHEIRO, 1997).

\section{Do Estado Democrático de Direito ao Estado de exceção}

\subsection{Violência Estrutural e violência institucional}

Ao examinar a questão da violência pelo ângulo do imbricamento entre o nível do desenvolvimento das forças produtivas e as relações de propriedade e poder na sociedade, Baratta (1990, p. 13-14) realiza uma aproximação das definições de violência estrutural em Karl MarX, no Século XIX e, na contemporaneidade dos Séculos XX e XXI, com Johan Galtung, que, apesar de situadas em contextos diferenciados, convergem para a noção de injustiça social.

Partindo desta concepção, Baratta (1990) define a violência estrutural como a forma geral de violência que serve de fonte para os outros tipos de violência que ele classifica: a) segundo o agente que a pratica; b) segundo a forma como é praticada; e c) segundo os sujeitos contra quem é praticada, esboçando uma categorização da violência que pode ser expressa no seguinte quadro classificatório (Figura 2):

Figura 2: Categorização da violência

\begin{tabular}{|c|c|}
\hline \multicolumn{2}{|c|}{$\begin{array}{c}\text { Violência Estrutural } \\
\text { (Repressão sistêmica das necessidades reais e dos } \\
\text { direitos humanos em seu conteúdo histórico e social) }\end{array}$} \\
\hline \multicolumn{2}{|c|}{$\downarrow$} \\
\hline \multicolumn{2}{|c|}{$\begin{array}{c}\text { Outras formas de violência direta ou indiretamente } \\
\text { derivadas da Violência Estrutural }\end{array}$} \\
\hline Segundo o agente & $\begin{array}{l}\text { - individual (praticada pelo indivíduo, } \\
\text { por motu próprio) } \\
\text { - de grupo (praticada por um grupo } \\
\text { social por meio de um indivíduo } \\
\text { particular) } \\
\text { - institucional (praticada por um } \\
\text { órgão do Estado, um governo, o } \\
\text { exército ou a policia) } \\
\text { - Internacional (praticada pela } \\
\text { administração de um Estado e se } \\
\text { dirige contra o governo ou o povo } \\
\text { de outro Estado) }\end{array}$ \\
\hline $\begin{array}{l}\text { Segundo a forma } \\
\text { como é praticada }\end{array}$ & $\begin{array}{l}\text { - direta } \\
\text { - indireta } \\
\text { - física } \\
\text { - moral } \\
\text { - etc }\end{array}$ \\
\hline $\begin{array}{l}\text { Segundo os sujeitos } \\
\text { contra quem é } \\
\text { praticada }\end{array}$ & $\begin{array}{l}\text { - contra minorias étnicas } \\
\text { - contra movimentos políticos e } \\
\text { sindicais } \\
\text { - contra grupos marginais } \\
\text { contra operário e trabalhadores do } \\
\text { campo } \\
\text { - contra mulheres } \\
\text { contra crianças } \\
\text { - eontra homossexuais } \\
\text { etc }\end{array}$ \\
\hline
\end{tabular}

Fonte: Criado pela autora a partir de Baratta (1990, p. 15).

A partir da definição extralegal de direitos humanos apresentada, em termos de necessidades reais, o referido autor desenhou uma classificação dos grupos fundamentais de direitos humanos, diferenciando-os em dois grupos: o primeiro integrado pelo direito à vida, à integridade física, à liberdade pessoal, à liberdade de opinião, de expressão e de religião e os direitos políticos. 0 segundo grupo, composto pelos direitos econômico-sociais: o direito ao trabalho, à educação, etc.

Em seguida, posicionando-se de dentro do espaço da criminologia crítica frente ao que denominou "fenomenologia global da violência", realizou quatro ordens de considerações relacionadas ao papel do direito penal e suas alternativas, referindo-se, na primeira delas, aos limites do sistema de justiça criminal como reação à violência e como defesa dos direitos humanos, alertando para a sua seletividade e para a pequena quantidade de infrações efetivamente alcançadas pelo sistema de controle penal.

Disto decorre, segundo o autor, a forma seletiva como a violência é percebida ou "construída" como problema social, desconsiderando alguns tipos de violência individual e considerando a violência de grupo e a violência institucional apenas em relação às ações de pessoas particulares, sem levar em consideração o conflito social que expressam.

\subsection{Estado e a violação do dever institucional de gestão eficiente do sistema prisional}

Costa (2005, p. 89) concluiu, em sua análise de diferentes abordagens sobre violência e controle social, que a violência acaba por ser uma construção política "resultado do confronto de jogos de interesses na vida social". Este confronto tem levado à ampliação do processo de criminalização na América Latina, e evidenciaria "um estado de segurança preventiva", denunciado em encontro organizado pelo Instituto Rosa Luxemburgo, na Escola Florestan Fernandes, onde várias organizações sociais apresentaram pesquisas e debateram o tema (PRADO, 2012).

Esse estado de coisas, concluiu o conclave, "se manifesta em uma multiplicidade de formas de controle, sob o argumento construído de que há contemporaneamente uma fragilidade do sistema punitivo diante de uma guerra social que ameaça cotidianamente o cidadão de bem". Materializa-se, assim, "a ideia de inimigo" na figura daquele a quem não é reconhecido o estatuto de sujeito de direito e "para quem as regras garantidas nos marcos constitucionais não valem" (PRADO, 2012).

Na mesma direção, Canotilho (2008, p. 236), ao estudar o impacto do discurso "anti-garantístico" sobre o direito fundamental à liberdade, analisou a repercussão dos discursos do "direito penal contra o inimigo" e afirmou que a utilização do direito penal não como ultima ratio, mas como instrumento de polícia e de cruzada contra os "inimigos", tem afetado um conjunto de princípios de direito penal e de direito processual que gozam de dignidade constitucional, promovendo modificações no campo doutrinário e no processo decisório, justificando "a ideia de res nullius em que se transformam os réus".

É a volta "do estado de exceção como estado de necessidade, sem as restrições do "direito de necessidade", com a transição de um "direito penal de permanência", para um "direito penal de emergência", no qual o funcionalismo sistémico, claramente assumido pelos defensores do "direito penal contra o inimigo", tem servido para justificar a coisificação dos réus, tornados seres destituídos de 
direitos fundamentais (CANOTILHO, 2008).

Baratta (1990, p.20), citando Foucault, afirma que o cárcere é um lugar privilegiado para a violação legal e extralegal de direitos humanos, afirmando também que, apesar dos progressos alcançados nas legislações penitenciárias mais modernas, na maior parte dos Estados a arbitrariedade e a violência no cárcere tendem a aumentar e alcançar graus extremos, conforme aumenta a violência estrutural na sociedade externa e, conforme se dá, de fato ou de direito, a suspensão das regras da democracia.

A pena, como alertou Baratta (1990), é uma violência institucional. Violenta, porém legalmente autorizada, a pena privativa de liberdade do indivíduo que realizou uma infração prevista na legislação penal passa a exercer funções materiais de reprodução e de institucionalização da desigualdade social, exercendo, também, as funções simbólicas de estereotipação de uma pequena fração da população recrutada no meio das camadas mais baixas da sociedade e de legitimação do modo de agir do sistema de justiça criminal e das relações sociais de desigualdade, porque é justamente nestes grupos mais baixos da escala social que se concentram aqueles que são aprisionados e rotulados como criminosos.

Deste modo, não apenas a desigualdade social fica "legitimada", como também passa a haver a sublimação da necessidade da garantia e da efetivação da proteção dos direitos mais elementares da população encarcerada, que, para além da superlotação carcerária e da violência física ou moral perpetrada por agentes do Estado ou por outros prisioneiros (ALMEIDA; PAES MACHADO, 2013), passa a sofrer um tipo de violência diverso, praticada exclusivamente pelo Estado e que agrava aqueles outros, a violência decorrente da deficiência na gestão da execução penal.

A ineficiência do Estado na gestão da pena privativa de liberdade, provisória ou definitiva, é agravada pela ausência de interoperabilidade dos sistemas utilizados pelos órgãos do sistema de justiça criminal, pois afeta os direitos das pessoas presas de forma negativa (na quase totalidade das vezes), por meio de situações que mantêm na invisibilidade a violência institucional que as produz e os seus efeitos concretos.

\section{São exemplos dessas situações:}

1. Ausência do registro da data de efetivação da prisão que não é oriunda de auto de prisão em flagrante, pois inviabiliza ou retarda a expedição da guia de recolhimento por ocasião da condenação.

2. Ausência de identificação criminal e da correta qualificação das pessoas submetidas à prisão (nos inquéritos, processos, decisões e demais atos do processo), porque possibilita a prisão e a condenação de pessoa diversa daquela que efetivamente praticou o fato ou a paralisação e o prolongamento da situação de prisão.

3. Desconhecimento do local da custódia da pessoa presa, por ausência de indicação nos documentos do processo e inexistência de um local de registro das movimentações com disponibilização para os órgãos competentes, porque acarreta: a) a impossibilidade de citação e intimação pessoal do réu; b) a decretação irregular de revelia; c) a suspensão indevida do processo pelo prazo prescricional; d) o reconhecimento indevido da prescrição; e) a decretação de prisão preventiva; f) a suspensão de audiências; g) o prolongamento do processo por impossibilidade de julgamento; d) o prolongamento da execução, por impossibilidade do deferimento de progressão de regime ou livramento condicional em virtude da existência de mandado de prisão preventiva.

4. Custódia em estabelecimento diverso do previsto na LEP, como carceragens de Delegacias da Polícia Civil, de Batalhões da Polícia Militar ou da Corregedoria da Polícia Civil, que gera a violação do direito à visita, ao banho de sol, à alimentação adequada, ao tratamento previsto na Lei de Execução Penal, inclusive para o preso provisório.

5. Ausência do registro, nas guias de recolhimento, das datas de concessão de liberdade provisória ou de fuga ao longo do processo, acarretando o atraso ou a impossibilidade de deferimento tempestivo da progressão de regime, do livramento condicional, do indulto e da comutação, porque impede a correta elaboração do cálculo da pena.

6. Atraso na expedição da guia de recolhimento, que torna impossível a abertura do processo de execução penal e do reconhecimento de qualquer dos direitos relativos a esta fase processual, gerando: a) imposição do regime fechado para quem foi condenado em regime semiaberto ou aberto ou, ainda, teve a pena de prisão substituída por pena restritiva de direitos; b) prolongamento do regime fechado por violação do prazo para progressão de regime; c) impossibilidade de expedição de alvará de soltura para cumprimento de pena restritiva de direito ou, até mesmo em virtude do cumprimento integral da pena.

7. Inexistência de Processo de Execução Penal, decorrente do não recebimento da guia de recolhimento ou da transferência do preso de uma unidade, de uma cidade ou de um estado para outro, sem a transferência do processo que: a) torna impossível o reconhecimento de qualquer dos direitos relativos a esta fase processual; b) prolonga o regime fechado; c) impede a expedição de alvará de soltura para cumprimento de pena restritiva de direito ou, mesmo, em virtude do cumprimento integral da pena ou da declaração de indulto ou de comutação.

8. Inexistência de sistema para cálculo automático da data do vencimento dos direitos e da pena, ocasionando omissão e atraso na apreciação e declaração dos direitos da pessoa condenada.

9. Transferência administrativa do preso, sem conhecimento do juízo de conhecimento ou da execução, que inviabiliza o andamento do processo de conhecimento, a transferência do processo de execução e o controle da legalidade do ato da administração prisional e impede o exercício dos seus direitos.

10. Não expedição de atestado de pena a cumprir, 
gerando para o preso e para o próprio estado gestor o desconhecimento dos prazos de vencimento do requisito temporal necessário à fruição dos direitos estabelecidos no Código Penal e na Lei de Execução Penal.

De natureza procedimental, estas violações que poderiam ser suprimidas pela existência e funcionamento de um sistema interoperável, nos moldes exigidos pela Lei $12.714 / 2012$, não são percebidas como violência institucional, mas o são porque decorrem da ação ou omissão dos membros dos órgãos integrantes do sistema de controle penal: policiais, promotores de justiça, juízes, diretores dos estabelecimentos penais. Essas violações são resultado da ausência de providências inerentes às atribuições legais e institucionais de cada órgão e podem ser evidenciadas de forma mais objetiva no seguinte quadro demonstrativo:

QUADRO 1: Quadro de evidências de violência institucional procedimental no sistema prisional

\begin{tabular}{|c|c|c|}
\hline $\begin{array}{l}\text { VIOLÊNCIA } \\
\text { INSTITUCIONAL }\end{array}$ & $\begin{array}{l}\text { NORMA } \\
\text { VIOLADA }\end{array}$ & $\begin{array}{l}\text { CONSEQUÊNCIAS DA } \\
\text { VIOLAÇÃO }\end{array}$ \\
\hline $\begin{array}{l}\text { 1. Ausência de } \\
\text { identificação e da } \\
\text { correta qualifi- } \\
\text { cação }\end{array}$ & \begin{tabular}{|l|} 
CPP (art. \\
$6^{\circ}$, VIII), Lei \\
$12.037 / 2009$, \\
Resolução 113 \\
do CNJ (art. 1 ${ }^{\circ}$, \\
I), Provimento \\
n. $^{\circ}$ CGJ - \\
$07 / 2010$ (art. \\
$4^{\circ}$, I)
\end{tabular} & $\begin{array}{l}\text { Condenação e prisão de } \\
\text { pessoa diversa da que } \\
\text { praticou a infração ou } \\
\text { paralisação do proces- } \\
\text { so e prolongamento da } \\
\text { situação de prisão. }\end{array}$ \\
\hline $\begin{array}{l}\text { 2. Ausência de } \\
\text { data da prisão }\end{array}$ & $\begin{array}{l}\text { CPP (arts. 286, } \\
\text { 288), Resolu- } \\
\text { ção 113 do CNJ } \\
\left.\text { (art. 1. }{ }^{\circ}, \mathrm{VIII}\right), \\
\text { Provimento } \\
\text { CGJ - 07/2010 } \\
\text { (art. 4. } .^{\circ} \text {, VIII) } \\
\end{array}$ & $\begin{array}{l}\text { Inviabilização da expe- } \\
\text { dição da guia de reco- } \\
\text { Ihimento. }\end{array}$ \\
\hline $\begin{array}{l}\text { 3. Desconheci- } \\
\text { mento do local da } \\
\text { custódia }\end{array}$ & $\begin{array}{l}\text { CPP (art. 306), } \\
\text { Resolução 113 } \\
\text { do CNJ (art. } \\
\left.1^{\circ}, \mathrm{X}\right), \text { Provi- } \\
\text { mento } \mathrm{n}^{\circ} \text { CGJ } \\
-07 / 2010 \text { (art. } \\
\left.4^{\circ}, \mathrm{X}\right) \\
\\
\end{array}$ & $\begin{array}{l}\text { Impossibilidade de } \\
\text { julgamento em tempo } \\
\text { razoável do processo } \\
\text { de conhecimento e dos } \\
\text { direitos correspon- } \\
\text { dentes ao processo de } \\
\text { execução penal (impos- } \\
\text { sibilidade de citação e } \\
\text { intimação pessoal do } \\
\text { réu; decretação irregu- } \\
\text { lar de revelia; suspen- } \\
\text { são do processo pelo } \\
\text { prazo prescricional; } \\
\text { decretação de prisão } \\
\text { preventiva; suspensão } \\
\text { de audiências; prolon- } \\
\text { gamento do processo } \\
\text { por impossibilidade de } \\
\text { julgamento; prolonga- } \\
\text { mento da execução, } \\
\text { por impossibilidade do } \\
\text { deferimento de progres- } \\
\text { são de regime ou livra- } \\
\text { mento condicional em } \\
\text { virtude da existência } \\
\text { de mandado de prisão } \\
\text { preventiva). }\end{array}$ \\
\hline $\begin{array}{l}\text { 4. Custódia em } \\
\text { local inadequado }\end{array}$ & \begin{tabular}{|l|} 
LEP (arts. 87 \\
a 104), Provi- \\
mento CGJ - \\
$07 / 2010$ (art. $1 \circ$ \\
e Anexo I)
\end{tabular} & $\begin{array}{l}\text { Violação do direito à } \\
\text { visita, ao banho de sol, } \\
\text { à alimentação adequa- } \\
\text { da e às assistências } \\
\text { previstas na Lei de } \\
\text { Execução Penal }\end{array}$ \\
\hline
\end{tabular}

\begin{tabular}{|c|c|c|}
\hline $\begin{array}{l}\text { 5. Atraso na expe- } \\
\text { dição da guia de } \\
\text { recolhimento }\end{array}$ & $\begin{array}{l}\text { Resolução } 113 \\
\text { do CNJ (art. } \\
\left.2^{\circ}, \S 1^{\circ}\right) \text {, Pro- } \\
\text { vimento CGJ } \\
-07 / 2010 \text { (art. } \\
\left.5^{\circ}, \S 2^{\circ}\right)\end{array}$ & \begin{tabular}{|l|} 
Imposição do regime \\
fechado para quem foi \\
condenado em regime \\
semiaberto ou aberto, \\
prolongamento do \\
regime fechado por \\
violação do prazo para \\
progressão de regime, \\
além do impedimento \\
da expedição de alvará \\
de soltura para cumpri- \\
mento de pena restritiva \\
de direito ou em virtude \\
do cumprimento inte- \\
gral da pena.
\end{tabular} \\
\hline $\begin{array}{l}\text { 6. Ausência de } \\
\text { informação das } \\
\text { datas de liberdade } \\
\text { e de fuga }\end{array}$ & $\begin{array}{l}\text { LEP (art. 106, } \\
\text { VI), Resolução } \\
113 \text { do CNJ } \\
\text { (art. } 1^{\circ}, \text { VIII), } \\
\text { Provimento } \\
\text { CGJ - 07/2010 } \\
\text { (art. } 4^{\circ}, \text { VIII) }\end{array}$ & $\begin{array}{l}\text { Impossibilidade de } \\
\text { deferimento tempes- } \\
\text { tivo da progressão de } \\
\text { regime, do livramento } \\
\text { condicional, do indulto } \\
\text { e da comutação, porque } \\
\text { impede a correta ela- } \\
\text { boração do cálculo de } \\
\text { liquidação da pena. }\end{array}$ \\
\hline $\begin{array}{l}\text { 7. Inexistência de } \\
\text { PEP }\end{array}$ & $\begin{array}{l}\text { LEP (art. 194), } \\
\text { Resolução } 113 \\
\text { do CNJ (arts. } \\
\left.1^{\circ}, 2^{\circ} \text { e } 3^{\circ}\right) \\
\text { Provimento } \\
\text { CGJ - 07/2010 } \\
\left(\text { art. } 6^{\circ}\right)\end{array}$ & $\begin{array}{l}\text { Impossibilidade do } \\
\text { reconhecimento de } \\
\text { qualquer dos direitos } \\
\text { relativos a esta fase } \\
\text { processual, prolongan- } \\
\text { do o regime fechado, } \\
\text { impedindo a expedição } \\
\text { de alvará de soltura } \\
\text { para cumprimento de } \\
\text { pena restritiva de direito } \\
\text { ou, mesmo, em virtude } \\
\text { do cumprimento inte- } \\
\text { gral da pena ou a decla- } \\
\text { ração de indulto ou de } \\
\text { comutação. }\end{array}$ \\
\hline $\begin{array}{l}\text { 8. Inexistência de } \\
\text { programa para } \\
\text { cálculo automa- } \\
\text { tizado }\end{array}$ & $\begin{array}{l}\text { Resolução } 113 \\
\text { do CNJ (art. } \\
\left.5^{\circ}\right) \text {, Provimento } \\
\text { CGJ - 07/2010 } \\
\left(\text { art. } 8^{\circ}\right)\end{array}$ & $\begin{array}{l}\text { Omissão e atraso na } \\
\text { apreciação e declaração } \\
\text { dos direitos da pessoa } \\
\text { condenada. }\end{array}$ \\
\hline $\begin{array}{l}\text { 9. Transferência } \\
\text { dos presos sem } \\
\text { conhecimento do } \\
\text { juízo de conhe- } \\
\text { cimento ou da } \\
\text { execução }\end{array}$ & $\begin{array}{l}\text { Resolução } 113 \\
\text { do CNJ (art. } \\
7 .^{\circ} \text {, } 11^{\circ} \text { ), Pro- } \\
\text { vimento CGJ - } \\
07 / 2010 \text { (arts. } \\
1^{\circ} \text { e } 10^{\circ} \text { ) }\end{array}$ & $\begin{array}{l}\text { Inviabilização da re- } \\
\text { messa do processo } \\
\text { de conhecimento ou } \\
\text { de execução para o } \\
\text { juízo competente, com } \\
\text { inviabilização do reco- } \\
\text { nhecimento dos direitos } \\
\text { correspondentes. }\end{array}$ \\
\hline $\begin{array}{l}\text { 10. Não expedi- } \\
\text { ção do atestado } \\
\text { de pena a cumprir }\end{array}$ & $\begin{array}{l}\text { LEP (art. } 41, \\
\text { XVI e } 66, x \text { ) }\end{array}$ & $\begin{array}{l}\text { Inviabilização do co- } \\
\text { nhecimento e exercício } \\
\text { tempestivo dos direitos } \\
\text { assegurados na LEP. }\end{array}$ \\
\hline
\end{tabular}

Fonte: Criado pela autora.

\section{Reconhecimento estatal e supraestatal da interoperabilidade como recurso tecnológico necessário}

\subsection{A previsão legal de interoperabilidade na gestão do sistema prisional}

A Lei 12.714, de 14 de setembro de 2012, que "dispõe sobre a o sistema de acompanhamento da execução das penas, da prisão cautelar e da medida de segurança" estabelece em seu artigo $5^{\circ}$ a instituição de um sistema nacional pelo Poder Executivo Federal "visando à interoperabilidade das bases de dados e informações dos sistemas informatizados instituídos pelos Estados e pelo Distrito Federal". Institui, também, a possibilidade de apoio para que as Unidades da Federação desenvolvam, implementem e promovam a adequação de sistemas próprios, de modo a permitir a interoperabilidade com o sistema nacional estatuído pela referida lei. 
O Ministério da Justiça, por intermédio de relatório publicado pelo Departamento Penitenciário - DEPEN/MJ em junho de 2015, produzido com dados coletados até 30 de junho de 2014 (BRASIL, 2015a, p. 11), reconheceu que a situação das prisões brasileiras desafia o sistema de justiça penal, a política criminal e a política de segurança pública e propôs uma política nacional de melhoria dos serviços penais sustentada em quatro eixos, um dos quais, a modernização do sistema penitenciário nacional por meio do:

[...]aumento de investimentos em tecnologia, para aprimorar procedimentos e garantir a segurança, e pelo aprimoramento da gestão de informações, para coletar e tratar dados que permitam o monitoramento integrado pelos órgãos de fiscalização das condições carcerárias de estabelecimentos críticos, o planejamento da gestão dos serviços penais e até mesmo o adequado acompanhamento da execução da pena de cada pessoa privada de liberdade (grifo nosso).

Os resultados divulgados, com atraso de mais de 12 meses da data da coleta e a informação de que os dados de São Paulo (UF responsável por $1 / 3$ da população carcerária) foram coletados apenas parcialmente, é a comprovação de que a ausência de interoperabilidade dos recursos tecnológicos utilizados para gestão do sistema prisional compromete o conhecimento da realidade.

Em confirmação a esta afirmação, o relatório revela que o sistema de unificação dos dados referentes à execução de penas, prisão cautelar e medida de segurança, previsto pela Lei $12.714 / 2012$, para ser dotado de interoperabilidade, ainda seria criado. No parágrafo seguinte afirma que esta ferramenta (Sisdepen) está em seu estágio final de desenvolvimento e "permitirá o acompanhamento individualizado do cumprimento das penas, por pessoa privada de liberdade, e o gerenciamento das informações penitenciárias, em nível nacional, por estado e por estabelecimento penal" (BRASIL, 2015a, p. 8). Esses resultados, contudo, ainda não foram entregues.

A eficiência do sistema de justiça criminal, como demonstram diversos estudos nos últimos quarenta anos (GOLDSTEIN, 1976; LEMGRUBER, 2001; ADORNO, 2002; SILVA JUNIOR, 2010), está vinculada ao nível desejado de coordenação, integração e sincronização existente entre a atuação dos diversos órgãos que o compõem, enquanto conjunto de instituições, estratégias e sanções sociais que constituem a instância formal de controle social penal.

Agir de forma desconectada, descoordenada, sem compartilhamento de dados e sem integração, desqualifica o sistema de justiça criminal como um todo, especialmente o sistema prisional porque torna imprecisos os dados concretos da violência individual, mascara a violência estrutural e oculta a violência institucional, propiciando a sua perpetuação e justificando a manutenção do paradigma da segurança como técnica de governo e de gestão (CARVALHO, 2013; AGAMBEN, 2004).

A possibilidade de manter presa uma pessoa por falta de identificação criminal ou impossibilidade de confirmação da invalidade de um mandado de prisão, ou ainda, por ausência da gestão adequada e correta da pena imposta na sentença condenatória, além de alimentar a superlotação carcerária, acaba por configurar-se como um capítulo do estado de "guerra civil legal" de que falou Agamben (2004), constituindo um estado de exceção permanente, do qual são exemplos as medidas denominadas "guerra ao terror" e "guerra às drogas".

Prado (2012), inclusive, confirmou a presença dos traços caracterizadores da suspensão de direitos fundamentais de que falou Canotilho (2008) e, portanto, comprobatórios da perenização do estado de exceção no Estado brasileiro, em pesquisa de campo que realizou no sistema prisional e nas Varas de Execuções Penais do Rio de Janeiro (RJ) e de João Pessoa (PB), com o objetivo de fazer um diagnóstico do sistema carcerário e do perfil daqueles presos. Naquele estudo, confirmando essa mutação ideológica que rompe com o princípio da legalidade e do garantismo constitucional, este autor percebeu, dentre outras situações, a

[...] desconstrução do princípio da legalidade a partir das não concessões dos benefícios do apenado, como progressão, comutação, dentre outros; da ausência de controle judicial das sanções disciplinares e do descaso diante de uma jurisdição que não observa o tempo de pena que o apenado deve cumprir impondo uma pena maior do que a inicialmente sentenciada (PRADO, 2012, p. 23).

Destacou, também no seu trabalho que

[...] um dos desafios no cotidiano das VEPs está na debilidade entre as informações da administração penitenciária e do sistema judicial. Notou-se, ao longo da pesquisa, que a falta de comunicação entre os sistemas é a causa de imprecisões acerca da situação jurídica dos presos, o que pode ter como consequência a violação de direitos relacionados à execução da pena (PRADO, 2012, p. 108) (grifos nossos).

Finalizando, recomendou a unificação dos Sistemas Virtuais de Informações das SEAPs (Secretarias de Administração Penitenciária) e das VEPs (Varas de Execuções Penais), observando a existência não somente de omissões, mas também de contradições entre as informações dos apenados fornecidas pela VEP e pela SEAP.

\subsection{A ONU e a interoperabilidade como ferramenta de desenvolvimento e governança}

A Assembleia Geral das Nações Unidas, com fundamento em Declarações e Resoluções anteriores sobre a proteção dos direitos humanos, proclamou a Resolução 3384, de 10 de novembro de 1975, segundo a qual- todos os Estados devem promover o progresso científico, para garantia do desenvolvimento econômico e social dos povos, sem sacrifício da efetividade dos direitos e liberdades humanas, de acordo com a Carta das Nações Unidas (ONU, 1975).

Esta Resolução foi desdobrada em documentos e programas posteriores da Divisão de Administração e Desenvolvimento de Gestão Pública do Departamento de Assuntos Econômicos e Sociais das Nações Unidas, que, desde 1999, por meio da UNPAN - sigla em inglês para Rede de Administração Pública das Nações Unidas - tem procurado capacitar os países em transição econômica, para responder aos desafios que os governos enfrentam 
para transpor o fosso digital entre os "ricos e pobres" e para atingir seus objetivos de desenvolvimento.

A UNPAN tem por objetivo o estabelecimento de uma rede baseada na internet para conexão das instituições regionais e nacionais dedicadas à administração pública e à construção da capacidade destas entidades para acessar, processar e disseminar informações relevantes através de uma infraestrutura de Tecnologia de Informação e Comunicação (TIC, ICT na sigla em inglês) atualizada e voltada para a promoção de uma melhor administração pública.

Por estas razões, a UNPAN tem funcionado como um suporte para os gestores na orientação das políticas e estratégias de governança eletrônica (e-Government), centrada principalmente na interoperabilidade como força motora do desenvolvimento sustentável, com o desafio de fornecer o suporte necessário, na área da tecnologia, para a realização das metas constantes da Declaração do Milênio (ONU, 2000; 2001).

Neste contexto, e tendo também como um marco a Declaração do Rio (ONU, 1992), a interoperabilidade passou a ser o motor propulsor, a peça-chave, do desenvolvimento sustentável, de acordo com os padrões estabelecidos consensualmente pelos países que integram a Organização das Nações Unidas, tanto na área dos negócios privados (e-business), como no mundo da governança dos Estados (e-Government), onde está inserido o tema da gestão do cumprimento das decisões criminais que implicam na total privação da liberdade de ir e vir das pessoas e no encarceramento em massa vivenciado na atualidade.

\section{CONSIDERAÇÕES FINAIS}

A interoperabilidade se apresenta em toda a sua interdisciplinaridade e transversalidade como uma solução a ser utilizada pelos órgãos do sistema de justiça criminal, não só para a garantia de eficiência na gestão da segurança pública, mas também, como garantia do respeito aos direitos fundamentais da liberdade e da dignidade da pessoa humana, enquanto princípios basilares e estruturantes dos estados democráticos de direito, conforme exigido pela Organização das Nações Unidas na Declaração Sobre o Uso do Progresso Científico e Tecnológico no Interesse da Paz e em Benefício da Humanidade, proclamada pela Assembleia Geral das Nações Unidas em 10 de novembro de 1975 por meio da Resolução 3384/1975.

Nas circunstâncias atuais de hiperencarceramento, a gestão do sistema prisional, sem o recurso da interoperabilidade dos sistemas tecnológicos, impede e dificulta que seja assegurada aos presos provisórios e condenados uma duração razoável do processo, a agilidade e a tempestividade do reconhecimento dos direitos assegurados pela legislação constitucional e infraconstitucional e, de modo mais específico, impede as pessoas condenadas o pleno gozo dos direitos correspondentes à progressividade e à antecipação do cumprimento da pena, como a mudança de regime, o livramento condicional, o indulto e a comutação.

Estas violações vitimizam a população encarcerada, suprimindo direitos fundamentais não afetados pelas decisões criminais justificadoras das prisões, e decorrem da falta de uma gestão eficiente do sistema por omissão dos órgãos e instituições responsáveis pela execução penal, em seu dever de gestão, fiscalização e decisão. Negam, também, vigência à legislação que tutela a matéria ao tornar invisível a violência efetivamente imposta pelo Estado, que ultrapassa os limites estabelecidos na decisão judicial autorizadora da privação da liberdade, em caráter provisório ou definitivo.

\section{REFERÊNCIAS}

ABBAGNANO, Nicola. Dicionário de filosofia. Trad. Alfredo Bosi 2. ${ }^{a}$ ed. São Paulo: Martins Fontes, 1988.

ADORNO, Sérgio. Crise no sistema de justiça criminal. Cienc. Cult., São Paulo, v. 54, n. 1, p. 50-1, jun. 2002 . Disponível em: <http://cienciaecultura.bvs.br/scielo.php?script=sci_ arttext\&pid $=$ S0009-67252002000100023\&lng $=$ en\&nrm $=i$ so>. Acesso em 25 jun. 2014.

AGAMBEN, Giorgio. Estado de Exceção. Trad. Iraci D. Poleti. São Paulo: Boitempo (Estado de sítio), 2004.

ALMEIDA, Odilza Lines de; PAES-MACHADO, Eduardo. Processos sociais de vitimização prisional. Tempo soc., São Paulo , v. 25, n. 1, p. 257-286, jun., 2013. Disponível em: $\quad<h t t p: / / w w w . s c i e l o . b r / s c i e l o . p h p ? s c r i p t=s c i$ arttext\&pid $=$ S0103-20702013000100013\&lng $=$ en\&nrm $=i$ so>. Acesso em: 22 ago. 2015.

BARATTA, Alessandro. Criminologia crítica e crítica do direito penal: introdução à sociologia do direito penal. Tradução Juarez Cirino dos Santos. 3 ed. Rio de Janeiro: Ed. Renavam: Instituto Carioca de Criminologia, 2002.

BATISTA, Vera Malaguti. O realismo marginal: criminologia, sociologia e história na periferia do capitalismo. In MELLO, Marcelo et al. Sociologia e Direito: Explorando Interseções. Niterói: PPGSD/UFF, 2007.

BOURDIEU, Pierre. 0 poder simbólico. Tradução Fernando Tomaz. $11^{\text {a }}$ ed. Rio de Janeiro: Bertrand Brasil, 2007.

BRASIL. Constituição da República Federativa do Brasil. Brasília: Senado Federal, 1988.

. E-PING - Padrões de Interoperabilidade de Governo Eletrônico - Documento de Referência Versão 2014, 2013. Disponível em: <http://eping.governoeletronico.gov.br>. Acesso em: 22 jun. 2014.

. Lei $\mathrm{n}^{\circ} 12.714$, de 14 de setembro de 2012. Dispõe sobre o sistema de acompanhamento da execução das penas, da prisão cautelar e da medida de segurança. Secretaria Especial Dos Direitos Humanos Da Presidência Da República - Sdh. Diário Oficial da União: Ministério Da Justiça. 2012b. Disponível em: <http://www.planalto. gov.br/ccivil_03/_Ato2011-2014/2012/Lei/L12714.htm>. Acesso em: 4 jan. 2015.

. Lei no 7.210 , de 11 de julho de 1984. Institui a Lei de Execução Penal. Diário Oficial da República Federativa do Brasil, 1984. Disponível em: <http://www.planalto.gov.br/ ccivil_03/LEIS/L7210.htm>. Acesso em: 17 out. 2015.

Ministério da Justiça. Departamento Penitenciário Nacional. Levantamento nacional de informações 
penitenciárias. INFOPEN - Junho de 2014, 2015b. Disponível em: <http://www.justica.gov.br/noticias/mjdivulgara-novo-relatorio-do-infopen-nesta-terca-feira/ relatorio-depen-versao-web.pdf>. Acesso em: 25 jun. 2015.

Ministério do Planejamento, Orçamento e Gestão. E-PING - Padrões de Interoperabilidade de Governo Eletrônico - Documento de Referência Versão 2015, 2014. Disponível em: <http://eping.governoeletronico.gov.br>. Acesso em: 4 jan. 2015.

Rede INFOSEG. Secretaria Nacional de Segurança Pública - SENASP, [s.d]. Disponível em: <http://www. infoseg.gov.br/paginas/rede-infoseg/historico>. Acesso em: 24 jul. 2014

Supremo Tribunal Federal. Responsabilidade da Administração. Recurso Extraordinário $n$. $^{\circ} \mathbf{5 8 0 . 2 5 2}$. Anderson Nunes da Silva e Estado de Mato Grosso do Sul. Relator: Ministro Teori Zavascki. Voto-vista Ministro Roberto Barroso, 2015a. Disponível em <http://www.stf.jus. $\mathrm{br} /$ arquivo/cms/noticiaNoticiaStf/anexo/RE580252LRB pdf> .Acesso em: 18 maio 2015.

BRETAS, Nazaré et. al. A Construção da e-PING: situação atual e desafios. In: BRASIL. Ministério do Planejamento, Orçamento e Gestão. Secretaria de Logística e Tecnologia da Informação. Panorama da interoperabilidade no Brasil. Org. Cláudia S. F. Mesquita e Nazaré L. Bretas. Brasília: MP/ SLTI, 2010, p. 16-23.

CANOTILHO, J.J. Gomes. Estado de Direito. Lisboa: Ed. Gradiva. 1999.

Direito Constitucional e Teoria da Constituição. 5. ed. Coimbra: Livraria Almedina. 2002.

Estudos sobre direitos fundamentais. 2. ed. Coimbra: Coimbra Editora, 2008.

CARVALho, Everaldo Jesus de. Escola Penitenciária: por uma gestão da educação prisional focada na dimensão pedagógica da função do agente penitenciário. 2013 115f. Dissertação (Mestrado) - Universidade do Estado da Bahia. Departamento de Educação. Pós-Graduação em Gestão e Tecnologias Aplicadas à Educação: Salvador, 2013.

CARVALHO, Salo. Criminologia crítica: dimensões, significados e perspectivas atuais. Revista Brasileira de Ciências Criminais, São Paulo, ano 1, v. 104, p. 279-303, out-set., 2013.

CASTRO, Lolita Aniyar de. Derechos humanos: delincuentes y víctimas, todos víctimas. Revista Electrónica del Centro de Investigaciones Criminológicas de la USMP, La Molina, $2^{\text {a }}$ ed., 2005. Disponível em: <http://www.derecho.usmp.edu. pe/centro_inv_criminologica/revista/revista_electronica2. htm>. Acesso em: 15 ago. 2015.

CONSELHO DA EUROPA. Convenção para a Proteç̧ão dos Direitos do Homem e das Liberdades Fundamentais. Roma: Conselho da Europa de Direitos Humanos, 1950. Disponível em: <http://www.echr.coe.int/Documents/Convention_ POR.pdf>. Acesso em: 25 jun. 2015.
COSTA, Ivone Freire. Polícia e sociedade. Gestão de segurança pública, violência e controle social. Salvador: EDUFBA, 2005.

FRANÇA . European Court of Human Rights - ECHR. Affaire Torregianni et autres c. Italie ( Requêtes n's 43517/09, $46882 / 09,55400 / 09,57875 / 09,61535 / 09,35315 / 10$ et 37818/10). Fermo-Mino Torreggiani, Bazoumana Bamba, Raoul Riccardo Biondi, Afrim Sela, Tarcisio Ghisoni, Mohamed El Haili e Radouane Hajjoubi c. Italie.Deuxiéme Section. Arrêt 8.01.2013. Disponível em: <http://hudoc. echr.coe.int/sites/eng/Pages/search.

GRADMANN, Stefan. Interoperability. A key concept for large scale, persistent digital libraries. HumboldtUniversitätzu: Berlin, 2008. Disponível em: <http://www. digitalpreservationeurope.eu/publications/briefs/english. php\#03>. Acesso em: 20 jun. 2014.

HABERMAS, Jurgen. Era das transições. Tradução e introdução de Flávio Siebeneichler, Rio de Janeiro: Tempo Brasileiro, 2003.

SILVA JUNIOR, Dequex Araújo. Segurança pública como cultura do controle. Revista Brasileira de Segurança Pública, São Paulo, v. 4, n.7, ago/set, 2010.

LEMGRUBER, Julita. Verdades e mentiras sobre o sistema de justiça criminal. R. CEJ, Brasília, v. 5, n. 15, p. 12-29, set./dez. 200. Disponível em: <http://www2.cjf.jus.br/ ojs2/index.php/revcej/article/view/427/608>. Acesso em: 25 jun. 2014.

MÜLLER, Friedrich. 0 novo paradigma do direito. Introdução à teoria e metódica estruturantes. São Paulo : Editora Revista dos Tribunais, 2007.

ORGANIZAÇÃO DOS ESTADOS AMERICANOS. Comissão interamericana de direitos humanos. Convenção Americana sobre Direitos Humanos. Assinada na Conferência Especializada Interamericana sobre Direitos Humanos. Costa Rica, 1969. Disponível em: <http://www.cidh. org/Basicos/Portugues/c.Convencao_Americana.htm>. Acesso em: 25 jun. 2015.

ORGANIZAÇÃO DAS NAÇÕES UNIDAS. Declaração sobre Meio Ambiente e Desenvolvimento - Rio 1992, Tradução da Rio Declaration, United Nations Conference on Environment and Development, Rio de Janeiro, Brasil, 3-14 de junho de 1992. Documento não traduzido oficialmente pela Organização das Nações Unidas. Disponível em: $<$ http://pactoglobalcreapr.files.wordpress.com/2010/10/ declaracao-do-rio-sobre-meio-ambiente.pdf>. 1992. Acesso em: 24 jul. 2014.

Regras mínimas para tratamento de prisioneiros. Adotadas pelo I Congresso das Nações Unidas sobre Prevenção do Crime e Tratamento de Delinqüentes, realizado em Genebra, em 1955, e aprovadas pelo Conselho Econômico e Social da ONU através da sua resolução 663 C I (XXIV), de 31 de julho de 1957, aditada pela resolução 2076 (LXII) de 13 de maio de 1977.

Resolução $n^{\circ}$ 3384, declaração sobre o uso do progresso científico e tecnológico no interesse da paz e em benefício da humanidade, proclamada pela Assembléia 
Geral das Nações Unidas em 10 de novembro de 1975, 1975. Disponível em: <http://www.direitoshumanos.usp. br/index.php/direito-ao desenvolvimento/declaracaosobre-o-uso-do-progresso-cientifico-e-tecnologico-nointeresse-da-paz-e-em-beneficio-da-humanidade.html>. Acesso em: 24 jul. 2014.

Resolução 55/2, United nations millenium declaration, de 08 de setembro de 2000, 2000. Disponível em: <http://www.un.org/millennium/declaration/ares552e. htm>. Acesso em: 24 jul. 2014.

Resolução 56/183, World Summit on the Information Society , de 21 de dezembro de 2001, 2001. Disponível em: <http://www.un-documents.net/a56r183.htm>. Acesso em: 24 jul. 2014.

PINHEIRO, Paulo Sérgio. Violência, crime e sistemas policiais em países de novas democracias. Tempo Social; Rev. Sociol. USP, São Paulo, v.9, n.1, p. 43-52, maio, 1997.

PRADO, Geraldo Luiz Mascarenhas. Lei de execução penal. Série Pensando o Direito, v. 44. Brasília: Ministério da Justiça, 2012.

SANTOS, Ernani Marques dos. Desenvolvimento e implementação da arquitetura e-PING: estratégias adotadas e possíveis implicações.In: BRASIL. Ministério do Planejamento, Orçamento e Gestão. Secretaria de Logística e Tecnologia da Informação. Panorama da interoperabilidade no Brasil. Brasília: MP/SLTI, 2010, p. 2437.

TRIBUNAL DE JUSTIÇA DO DISTRITO FEDERAL E DOS TERRITÓRIOS. Tribunal do DF inicia testes com o módulo Escritório Digital. Processo Judicial Eletrônico - PJe, Brasília: Diário de Justiça, 2015. Disponível em: < http:// www.cnj.jus.br/noticias/judiciario/79404-tribunal-do-dfinicia-testes-com-o-modulo-escritorio-digital>. Acesso em: 25 jun. 2015.

ZAGREBELSKY, Gustavo. El derecho dúctil. Lei, derechos, justicia. Traduzido por Marina Gascón. 9. ${ }^{a}$ ed. Madrid: Editorial Trotta, 2009. 


\section{Andremara dos Santos}

Doutoranda pela Universidade Nova de Lisboa em Direito Constitucional, Mestre em Direito Economico (1997) e em Segurança Pública Justiça e Cidadania pela Universidade Federal da Bahia (2015). Especialista em Processo Civil pela Fundação Faculdade de Direito da Bahia (1994) e Segurança Pública pela Universidade Estadual da Bahia e Università degli Studi di Padova (2015). Graduada em Direito pela Universidade Federal da Bahia (1984). Pesquisadora Convidada do Max-PlanckInstitut für Ausländisches öffentliches Recht und Völkerrecht, em Heidelberg, no período de agosto a outubro de 2001, mediante bolsa da Fundação Calouste Gulbenkian. Estagiária Visitante do Tribunal Geral da União Européia, então Tribunal de Primeira Instância, em 2001. Juíza de Direito Substituta do Segundo Grau no Tribunal de Justiça da Bahia, convocada e nomeada Secretária-Geral da Presidência do Supremo Tribunal Federal (2016), designada Juíza Auxiliar da Presidência do Conselho Nacional de Justiça (2017). 